\title{
Ion Conducting Behaviour of Nano Dispersed Polymer Gel Electrolytes Containing $\mathrm{NH}_{4} \mathrm{PF}_{6}$
}

\author{
Jitender P. Sharma and S.S. Sekhon * \\ Department of Applied Physics, G. N. D. University, Amritsar-143005, India
}

Received 4 April 2008; accepted 22 September 2008

\begin{abstract}
The effect of addition of nano size fumed silica on the conductivity and viscosity behaviour of polymer gel electrolytes containing polyethylene oxide (PEO), ammonium hexafluorophosphate $\left(\mathrm{NH}_{4} \mathrm{PF}_{6}\right)$ and propylene carbonate $(\mathrm{PC})$ has been studied. The addition of PEO increases the viscosity of electrolytes alongwith a small increase in conductivity and polymer gel electrolytes with conductivity higher than the corresponding liquid electrolytes have been obtained. Increase in conductivity with the addition of PEO and fumed silica has been explained to be due to the dissociation of ion aggregates, which is also supported by FTIR results. The thermal stability of polymer gel electrolytes improves marginally with the addition of fumed silica. The conductivity of nano dispersed gels does not show much change over $20-100{ }^{\circ} \mathrm{C}$ temperature range and also remains constant with time.
\end{abstract}

Keywords: conductivity, viscosity, fumed silica, FTIR, DSC/TGA.

\section{Introduction}

Polymer gel electrolytes obtained by the immobilization of salt solution with the addition of a suitable polymer matrix are important due to their high ionic conductivity which is higher than for solvent free polymer electrolytes [1-2]. Polymer gel electrolytes containing lithium salts have been widely studied due to their suitability as solid electrolytes in lithium batteries [2-4]. Proton conducting polymer gel electrolytes are also important due to their potential use in different devices [5-6]. Polymer gel electrolytes belong to salt-solvent-polymer hybrid system in which solvent is retained in the electrolyte and possess conductivity comparable to that of liquid electrolytes [7-11]. The solvent provides conducting medium but gel electrolytes with large amount of solvent are not mechanically strong for practical applications. The addition of polymer to salt solution increases the viscosity, which is generally accompanied by a small

\footnotetext{
*Corresponding author. E-mail address: sekhon_apd@yahoo.com
} 
decrease in conductivity [12]. In solvent free polymer electrolytes, the addition of micron size inorganic fillers such as fumed silica, zeolite, $\mathrm{Al}_{2} \mathrm{O}_{3}, \mathrm{TiO}_{2}$, etc., has been reported to result in an improvement in the electrode-electrolyte interfacial stability, conductivity along with an improvement in mechanical properties of electrolytes [1316]. The aim of the present work is to study the effect of nano size fumed silica on the properties of polymer gel electrolytes.

In the present work, nano dispersed gel electrolytes containing, $\mathrm{PMMA}, \mathrm{NH}_{4} \mathrm{PF}_{6}$ and PC have been studied. The effect of addition of nano size fumed silica on conductivity, viscosity and thermal properties of gel electrolytes has been studied. The presence of ion aggregates and their dissociation with the addition of PEO and fumed silica has been studied by FTIR.

\section{Experimental}

$\mathrm{NH}_{4} \mathrm{PF}_{6}$ (Aldrich), PEO (Aldrich, $\mathrm{M}_{\mathrm{w}}=5 \times 10^{6}$ ), fumed silica (Aldrich) with average particle size $7 \mathrm{~nm}$ and PC (Merck) were used as the starting materials for the preparation of polymer gel electrolytes. Fumed silica in different concentrations (expressed as wt $\%$ of polymer gel electrolytes) was added to polymer gel electrolytes alongwith continuous stirring till a homogeneous mixture is obtained. The conductivity was measured by complex impedance spectroscopy with computer interfaced Hioki 3532-50 Hi Tester using a cell with platinum electrodes. Viscosity of different electrolytes was measured by using Fungilab rotating viscometer (Visco Basic L) and temperature was maintained by Julabo water circulator (F-12EC). FTIR spectra were recorded (at $25^{\circ} \mathrm{C}$ ) with a computer interfaced Shimadzu 8400S FTIR spectrometer. Thermal properties of gel electrolytes were studied by simultaneous Differential Scanning Calorimetry (DSC) and Themogravimetric Analysis (TGA) (SDT Q600 V8.0 Build 95) in the $25-300{ }^{\circ} \mathrm{C}$ temperature range at the heating rate of $10{ }^{\circ} \mathrm{C} /$ minute under nitrogen atmosphere.

\section{Results and discussion}

The conductivity of electrolytes $\left(\mathrm{PC}-\mathrm{NH}_{4} \mathrm{PF}_{6}\right)$ was measured as a function of salt concentration (Fig. 1). The conductivity of PC $\left(\sim 10^{-6} \mathrm{~S} / \mathrm{cm}\right)$ increases by four orders of magnitude to $10^{-2} \mathrm{~S} / \mathrm{cm}$ with the addition of $\mathrm{NH}_{4} \mathrm{PF}_{6}$. The increase of conductivity is not uniform at all salt concentrations and is slow at higher salt concentrations, which is possibly due to the formation of ion aggregates, which do not contribute to the conduction process [17]. Fig. 2 shows the variation of conductivity of polymer gel electrolytes as a function of PEO concentration. The conductivity shows a marginal increase at very low concentrations of PEO and then decreases by a small factor at higher concentrations of PEO, but still gels have conductivity of the same order $\left(10^{-2} \mathrm{~S} / \mathrm{cm}\right)$ as observed for liquid electrolytes. With the addition of PEO the viscosity of gel electrolytes increases which lowers mobility and as a result conductivity decreases (Fig. 2). 


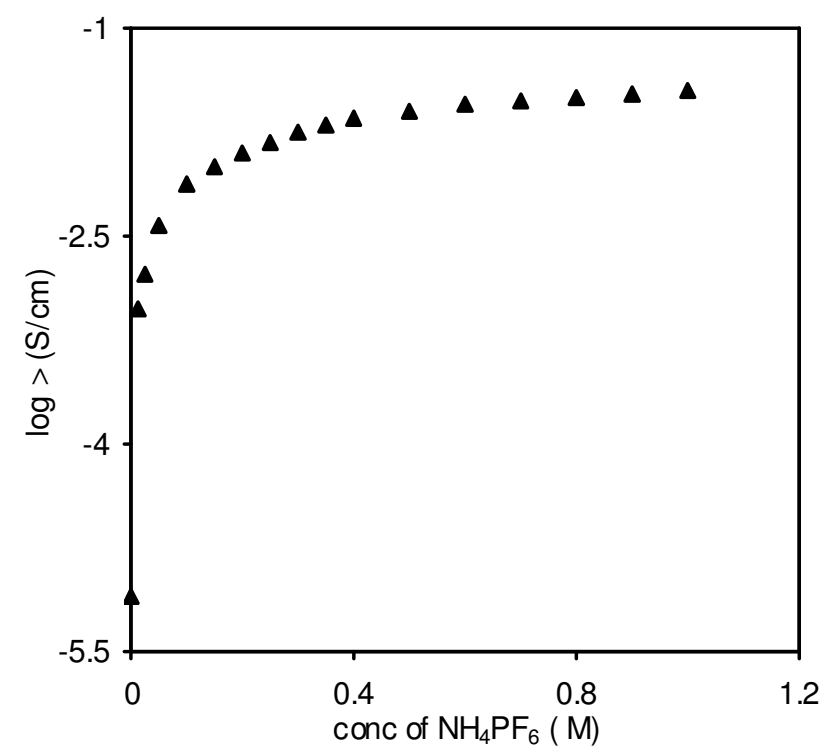

Figure 1. Variation of conductivity $(\sigma)$ of liquid electrolytes $\left(\mathrm{PC}-\mathrm{NH}_{4} \mathrm{PF}_{6}\right)$ with the concentration of $\mathrm{NH}_{4} \mathrm{PF}_{6}$ in $\mathrm{PC}$.

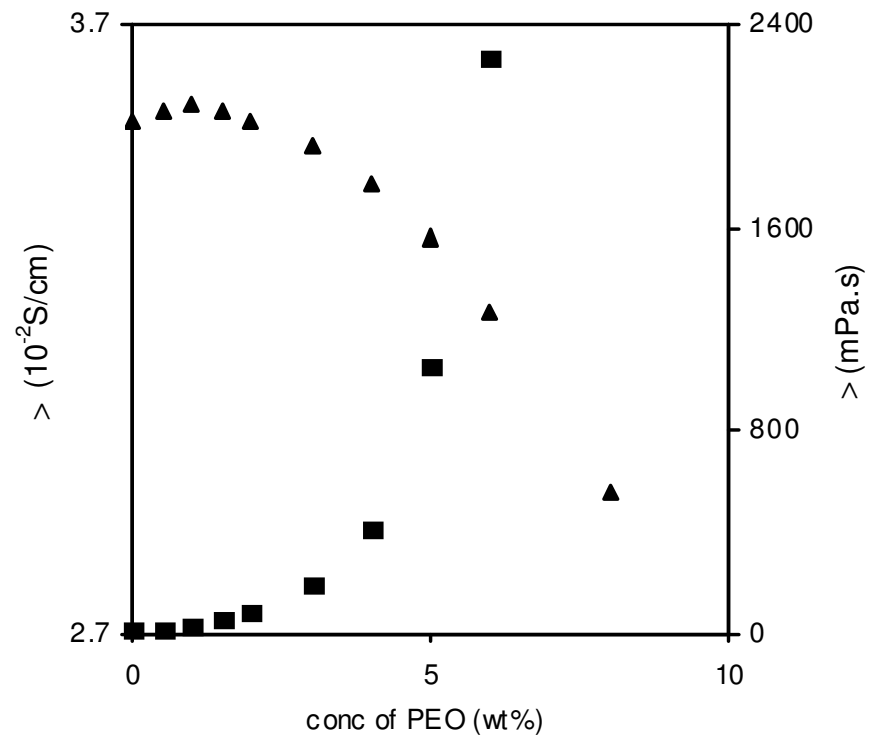

Figure 2. Dependence of conductivity $(\sigma)(\boldsymbol{\Lambda})$ and viscosity $(\eta)(\boldsymbol{\bullet})$ on the concentration of PEO for electrolytes containing $1 \mathrm{M} \mathrm{NH}_{4} \mathrm{PF}_{6}$ in PC.

However the small increase in conductivity at very low concentration of PEO is possibly due to the role of PEO in enhancing free ion concentration by dissociating ion aggregates/undissociated salt present in these electrolytes, which has also been studied by FTIR. The FTIR spectra of different electrolytes in the $700-2000 \mathrm{~cm}^{-1}$ wave number region are given (Fig. 3). The peak at $1789 \mathrm{~cm}^{-1}$ $(\mathrm{C}=\mathrm{O})$ of $\mathrm{PC}[18]$ in liquid electrolytes gets broadened due to its overlapping with the $1793 \mathrm{~cm}^{-1}$ peak of PEO [19], which suggests that PEO chains affect $\mathrm{C}=\mathrm{O}$ group of PC. In liquid electrolytes, the peaks at 742 and $842 \mathrm{~cm}^{-1}$ have been 
assigned to free $\mathrm{PF}_{6}^{-}$anions. The shoulder at $856 \mathrm{~cm}^{-1}$ is due to the ion aggregates, which are present in electrolytes containing higher concentrations of salt. Aroca et al. [20] have also assigned $845 \mathrm{~cm}^{-1}$ band to free $\mathrm{PF}_{6}{ }^{-}$anions and $867 \mathrm{~cm}^{-1}$ band to ion pairs. The peak at $1290 \mathrm{~cm}^{-1}$ is due to the presence of $\mathrm{NH}_{4} \mathrm{PF}_{6}$ in liquid electrolytes. The peak at $1402 \mathrm{~cm}^{-1}$, due to $\mathrm{H}-\mathrm{N}-\mathrm{H}$ bending of $\mathrm{NH}_{4}{ }^{+}$ion, shifts to $1392 \mathrm{~cm}^{-1}$ in liquid electrolytes alongwith the appearance of a shoulder at $1428 \mathrm{~cm}^{-1}$, which has been assigned to be due to ion aggregates. The disappearance of peak at $1290 \mathrm{~cm}^{-1}$ and shoulder at $1428 \mathrm{~cm}^{-1}$, with the addition of PEO, is due to the dissociation of undissociated salt/ion aggregates, leading to an increase in free ion concentration as proposed above, which enhances the conductivity of electrolytes.

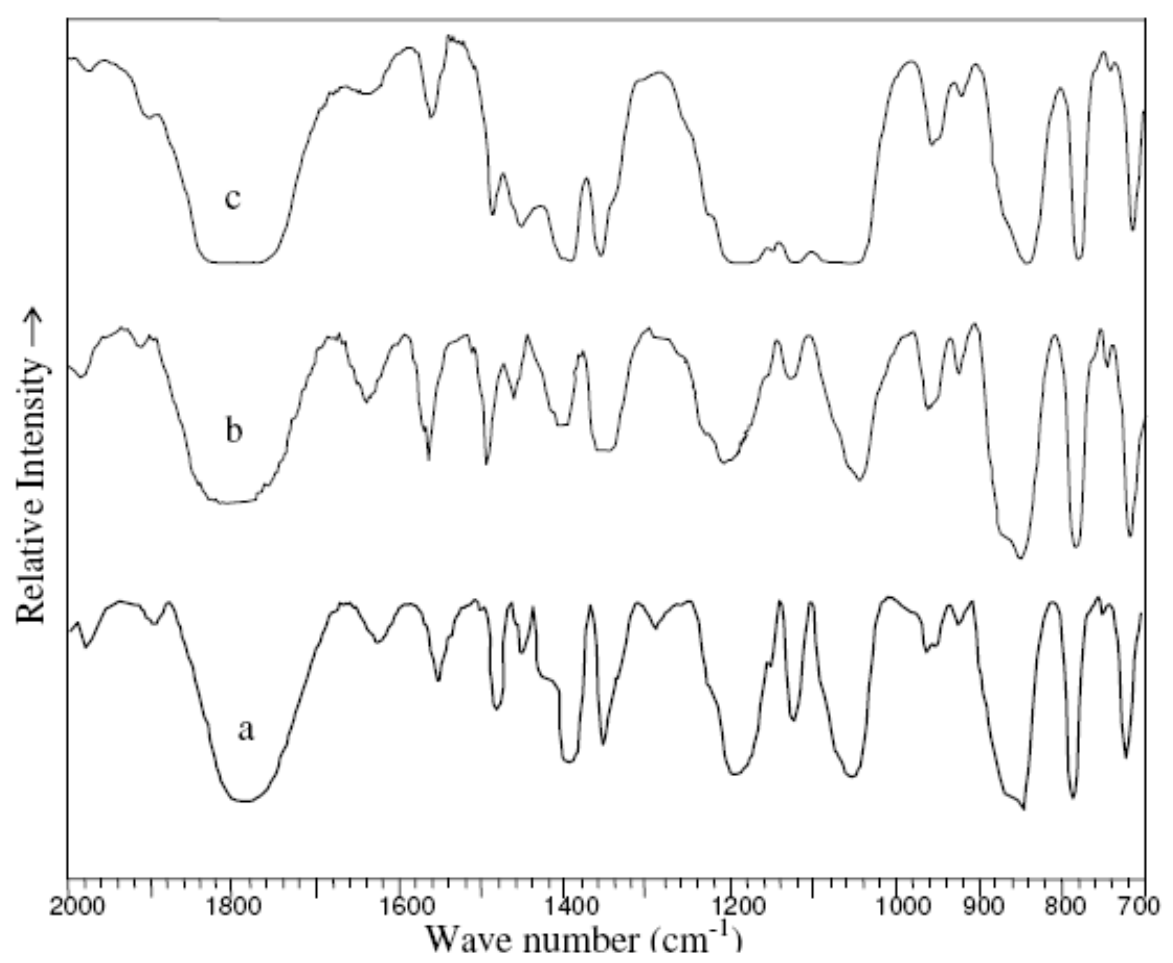

Figure 3. FTIR spectra of (a) $\mathrm{PC}+1 \mathrm{M} \mathrm{NH}_{4} \mathrm{PF}_{6}$, (b) $\mathrm{PC}+1 \mathrm{M} \mathrm{NH}_{4} \mathrm{PF}_{6}+1$ wt $\% \mathrm{PEO}$ and (c) $\mathrm{PC}+1 \mathrm{M} \mathrm{NH}_{4} \mathrm{PF}_{6}+1 \mathrm{wt} \% \mathrm{PEO}+1 \mathrm{wt} \%$ fumed silica in wave number regions of $700-$ $2000 \mathrm{~cm}^{-1}$.

Fig. 4 shows the variation of conductivity of polymer gel electrolytes with the concentration of fumed silica. The conductivity of polymer gel electrolytes increases with the addition of fumed silica, and two maxima have been observed in the conductivity variation at very low concentrations of fumed silica. After the position of second maxima, the conductivity shows a continuous decrease, which is due to higher viscosity of the electrolytes and blocking of conducting pathways by the grains of fumed silica which hinders the motion of mobile ions [21]. The initial increase in conductivity at very low concentration of fumed silica is due to an increase in free ion concentration, which may take place due to the dissociation of ion aggregates present in these gel electrolytes. The presence of ion aggregates in polymer gel electrolytes and their dissociation with the addition 
of fumed silica was studied by FTIR. In the FTIR spectra (Fig. 3) $\mathrm{C}=\mathrm{O}$ stretching vibrational band of $\mathrm{PC}$ at $1793 \mathrm{~cm}^{-1}$ has been observed to broaden with the addition of fumed silica. The shoulder at $856 \mathrm{~cm}^{-1}$ (due to ion aggregates) has been found to disappear with the addition of fumed silica. Thus the interactions between fumed silica and polymer gel electrolyte also contribute to conductivity enhancement by dissociating ion aggregates present in these electrolytes.

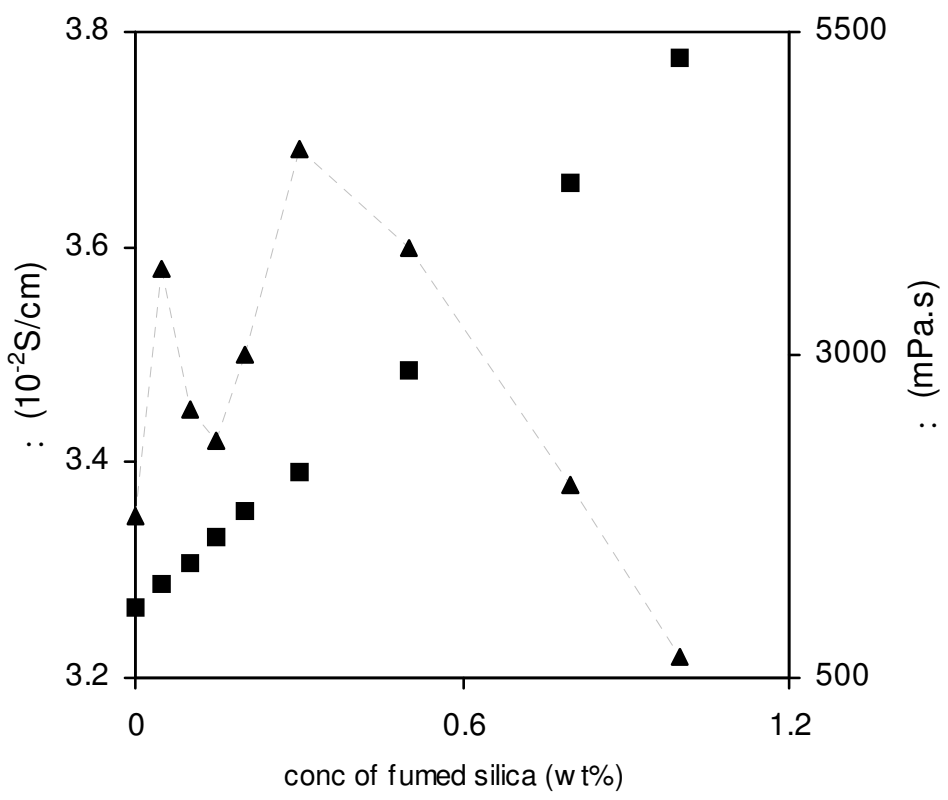

Figure 4. Dependence of conductivity $(\sigma)(\boldsymbol{\Delta})$ and viscosity $(\eta)(\boldsymbol{\square})$ on the concentration of fumed silica for electrolytes containing $1 \mathrm{M} \mathrm{NH}_{4} \mathrm{PF}_{6}$ in $\mathrm{PC}$.

The second conductivity maxima has been observed at relatively higher concentration of fumed silica, where the viscosity is large and it is related to the formation of a highly conductive interfacial layer between the particles of fumed silica and polymer gel electrolytes, and is generally known as the composite effect. After the second conductivity maxima, the conductivity decreases continuously with an increase in the concentration of fumed silica. It is due to the dominant role played by viscosity, which was also measured and its variation with the concentration of fumed silica is given (Fig. 4).

Thermal stability of polymer gel electrolytes and nano dispersed gels has been studied by simultaneous DSC/TGA measurements and the results are given (Fig. 5 ). An endothermic peak in the temperature range $50-80{ }^{\circ} \mathrm{C}$, corresponding to the weight loss of $<2 \%$ has been observed which is attributed to be due to the melting of PEO $\left(\mathrm{T}_{\mathrm{m}}=65{ }^{\circ} \mathrm{C}\right)$. After the addition of nano size fumed silica to polymer gel electrolytes, the above melting isotherm gets broadened, possibly due to the interaction of fumed silica particles with the constituents of polymer gel electrolytes. Small exothermic peak at $110{ }^{\circ} \mathrm{C}$ corresponding to weight loss of $5 \%$ has been observed in polymer gel electrolytes, which may be due to the evaporation of residual moisture absorbed when the sample was loaded. 


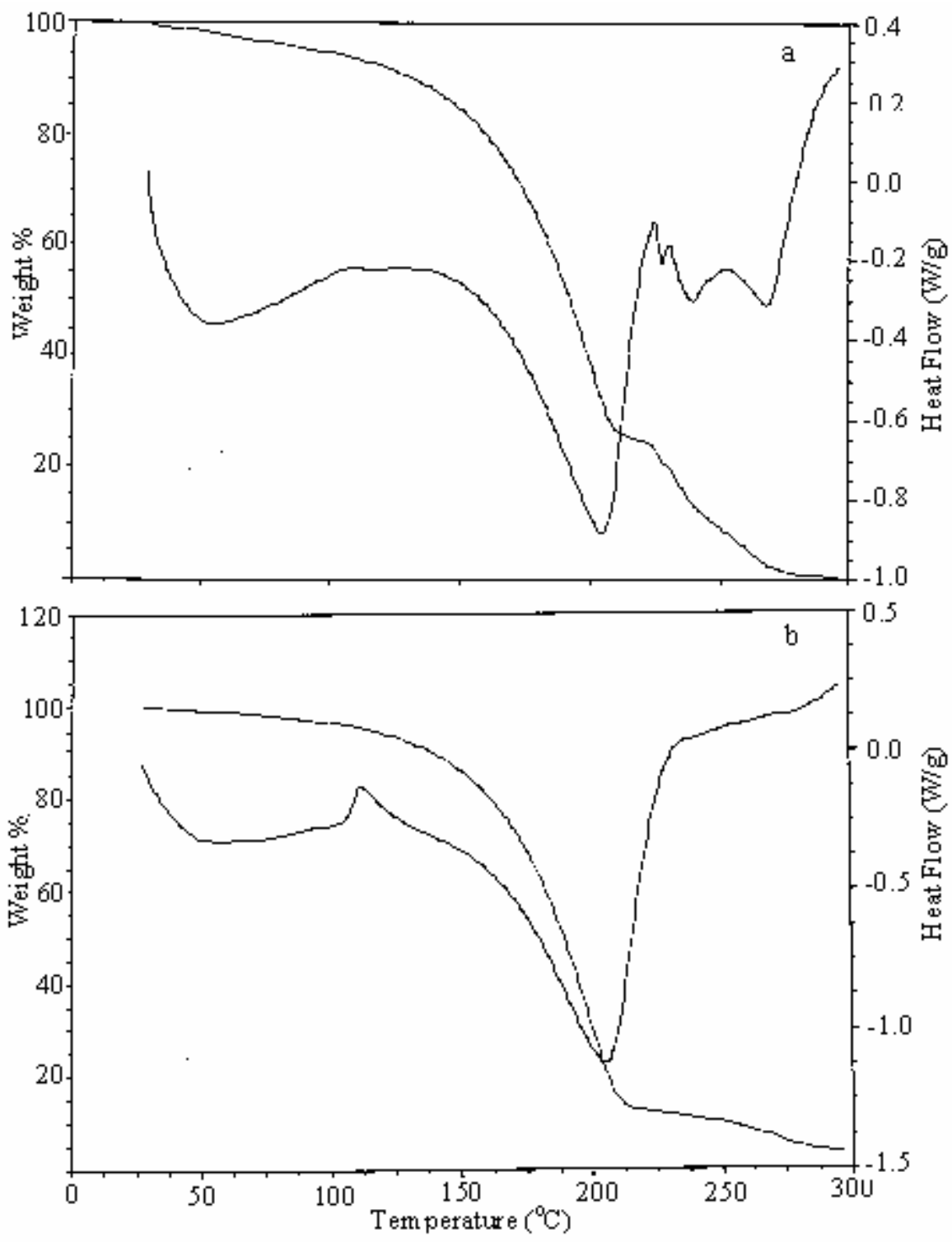

Figure 5. DSC and TGA plots for electrolytes having composition (a) $\mathrm{PC}-1 \mathrm{M} \mathrm{NH}_{4} \mathrm{PF}_{6}$ $1 \mathrm{wt} \%$ PEO and (b) PC-1 M NH $\mathrm{PF}_{6}-1 \mathrm{wt} \%$ PEO- $1 \mathrm{wt} \%$ fumed silica.

This peak becomes more apparent in nano dispersed gels due to the interaction of surface hydroxyl groups of fumed silica particles with polymer gel electrolytes. Decomposition temperature corresponding to weight loss of $10 \%$ has been observed at 130 and $138{ }^{\circ} \mathrm{C}$ in polymer gel electrolytes and nano dispersed gels, respectively. This shows that the addition of fumed silica marginally improves the thermal stability of electrolytes. An endothermic peak at $202{ }^{\circ} \mathrm{C}$ with a weight loss of $66 \%$ has been attributed to be due to the thermal decomposition of polymer in electrolytes. Rapid weight losses of $80 \%$ and $87 \%$ have been observed corresponding to two endothermic peaks at 228 and $240{ }^{\circ} \mathrm{C}$, respectively, due to the evaporation of PC (boiling point $=242{ }^{\circ} \mathrm{C}$ ) in polymer gel electrolytes. 


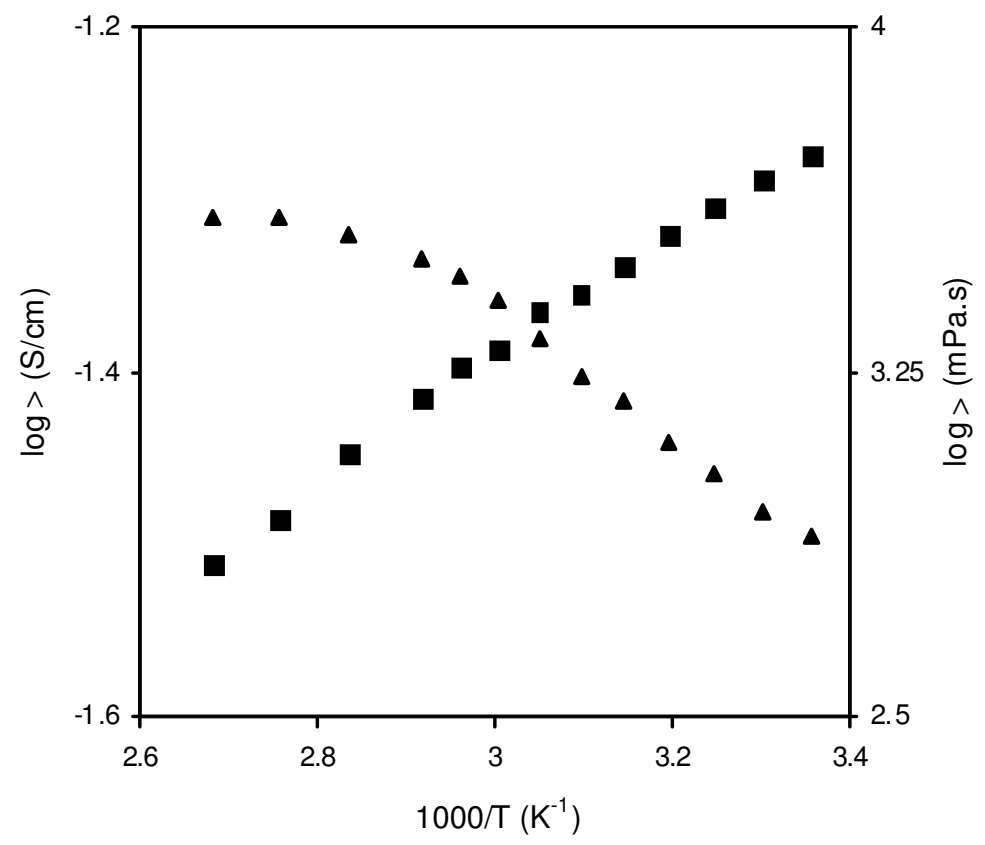

Figure 6. $\log$ conductivity $(\boldsymbol{\Delta})$ and $\log$ viscosity (a) vs. reciprocal temperature for polymer gel electrolytes containing $1 \mathrm{wt} \%$ fumed silica.

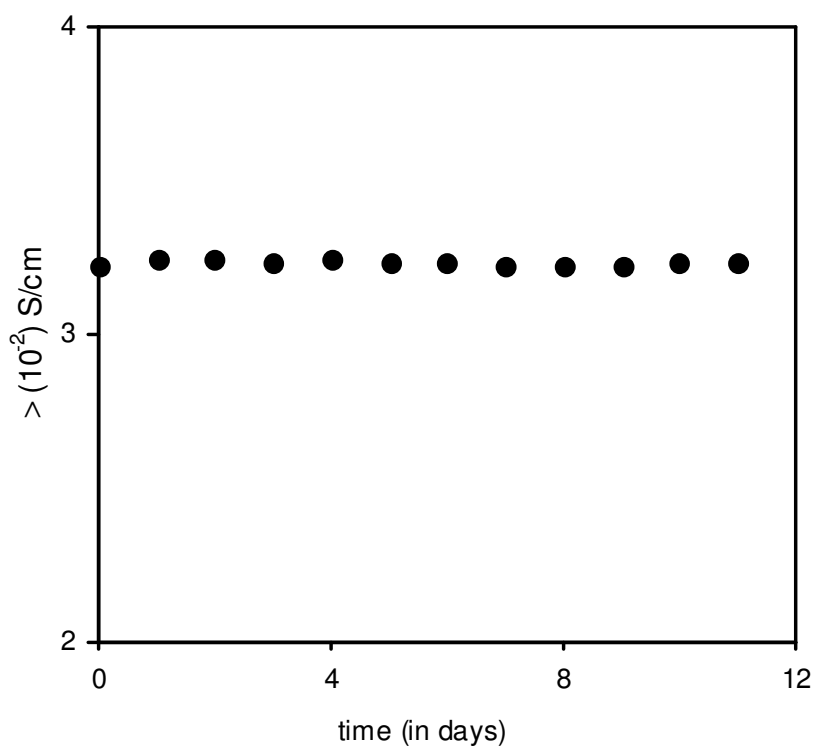

Figure 7. Variation of conductivity with time for nano dispersed gels containing $1 \mathrm{M}$ $\mathrm{NH}_{4} \mathrm{PF}_{6}$ having $1 \mathrm{wt} \%$ fumed silica.

The dependence of conductivity and viscosity of nano dispersed polymer gel electrolytes upon temperature was also studied and the variation of log conductivity and log viscosity with reciprocal temperature is given (Fig. 6). Over the $25-100{ }^{\circ} \mathrm{C}$ temperature range, the conductivity of nano dispersed gels shows only a small increase. Fig. 7 shows that the conductivity of nano dispersed gels 
does not show any appreciable change with time over a limited period of 10 days, which is desirable from application point of view.

\section{Conclusions}

The dispersion of fumed silica to polymer gel electrolytes results in nano dispersed gels with conductivity of the order of $10^{-2} \mathrm{~S} / \mathrm{cm}$. The addition of PEO and fumed silica results in an increase in conductivity which has been found to be due to an increase in free ion concentration with the dissociation of ion aggregates / undissociated salt and this has been supported by FTIR results. A small change in conductivity and viscosity observed over the $20-120{ }^{\circ} \mathrm{C}$ temperature range alongwith constant value of conductivity with time is desirable for their potential use in different applications.

\section{Acknowledgements}

One of the authors (SSS) is thankful to DST New Delhi for financial support in the form of a research scheme No.SR/S2/CMP-54/2003.

\section{References}

1. M. Watanabe, M. Kanba, K. Nagaoka, I. Shinohara, J. Polym. Sci. Polym. Phys. 21 (1983) 939.

2. K.M. Abraham, M. Alamgir, J. Electrochem. Soc. 137 (1990) 1657.

3. G. Feuillade, P. Perche, J. Appl. Electrochem. 5 (1975) 63.

4. R. Koksbang, I.I. Olsen, D. Shackle, Solid State Ionics 69 (1994) 320.

5. P. Colomban (Ed.), in Proton Conductors: Solids, Membranes and GelsMaterials and Devices, Cambridge University Press, Cambridge, 1992.

6. K.D. Kreuer, Solid State Ionics 97 (1997) 1.

7. S. Chandra, S.S. Sekhon, N. Arora, Ionics 6 (2000) 112.

8. A.M. Grillone, S. Panero, B.A. Retamal, B. Scrosati, J. Electrochem. Soc. 146 (1999) 27.

9. S.S. Sekhon, Bull. Mater. Sci. 26 (2003) 321.

10. S. Chandra, S.S. Sekhon, R. Srivastava, N. Arora, Solid State Ionics 154155 (2002) 609.

11. R. Kumar, J.P. Sharma, S.S. Sekhon, Eur. Polym. J. 41 (2005) 2718.

12. M. Deepa, N. Sharma, S. A. Agnihotry, S. Singh, T. Lal, R. Chandra, Solid State Ionics 152-153 (2002) 253.

13. J.E. Weston, B.C.H. Steele, Solid State Ionics 7 (1982) 75.

14. H.Y. Sun, H. J. Sohn, O. Yamamoto, Y. Takeda, N. Imanishi, J. Electrochem. Soc. 146 (1999) 1672.

15. B. Scrosati, F. Croce, L. Persi, J. Electrochem. Soc. 147 (2000) 1718.

16. S. Slane, M. Solomon, J. Power Sources 55 (1995) 7.

17. P.G. Bruce, Synth. Met. 45 (1991) 267.

18. D. Battisti, G.A. Nazri, B. Klassen, R. Aroca, J. Phys Chem. 97 (1993) 5826. 
19. B.L. Papke, M.A. Ratner and D.F. Shriver, J. Phys. Chem. Solids 42 (1981) 493.

20. R. Aroca, M. Nazri, G.A. Nazri, A.J. Camargo, M.J. Trsic, Solution Chem. 29 (2000) 1047.

21. C. Capiglia, P. Mustarelli, E. Quartarone, C. Tomasi, A. Magistris, Solid State Ionics 118 (1999) 73. 